\title{
Nanostructured polymer-titanium composites and titanium oxide through polymer swelling in titania precursor
}

\author{
A. Kierys $・$ R. Zaleski $\cdot$ W. Buda $\cdot$ S. Pikus $\cdot$ \\ M. Dziadosz • J. Goworek
}

Received: 13 June 2012 /Revised: 2 November 2012 / Accepted: 9 December 2012 /Published online: 27 December 2012

(C) The Author(s) 2012. This article is published with open access at Springerlink.com

\begin{abstract}
Polymer (XAD7HP)/ $/ i^{4+}$ nanocomposites were prepared through the swelling of polymer in titanium (IV) ethoxide as a titanium dioxide precursor. The nanocomposite beads exhibit relatively high porosity different than the porosity of the initial polymer. Thermal treatment of composite particles up to $200{ }^{\circ} \mathrm{C}$ in vacuum causes the change of their internal structure. At higher temperature, the components of composite become more tightly packed. Calcination at $600{ }^{\circ} \mathrm{C}$ and total removal of polymer produce spherically shaped $\mathrm{TiO}_{2}$ condensed phase as determined by XRD. Thermally treated composites show the substantial change of pore dimensions within micro- and mesopores. The presence of micropores and their transformation during thermal processing was studied successfully by positron annihilation lifetime spectroscopy (PALS). The results derived from PALS experiment were compared with those obtaining from low-temperature nitrogen adsorption data.
\end{abstract}

Keywords Composite $\cdot$ Titanium dioxide $\cdot$ Positron annihilation lifetime spectroscopy (PALS)

A. Kierys $(\triangle) \cdot$ W. Buda $\cdot$ M. Dziadosz $\cdot$ J. Goworek Department of Adsorption, Faculty of Chemistry,

M. Curie-Sklodowska University, M. Curie-Sklodowska sq. 3, 20-031 Lublin, Poland

e-mail: agnieszka.kierys@umcs.lublin.pl

R. Zaleski

Department of Nuclear Methods, Institute of Physics,

M. Curie-Sklodowska University, M. Curie-Sklodowska sq. 1, 20-031 Lublin, Poland

\section{S. Pikus}

Department of Crystalography, Faculty of Chemistry,

M. Curie-Sklodowska University, M. Curie-Sklodowska sq. 3, 20-031 Lublin, Poland

\section{Introduction}

In recent years, titania dioxide have attracted a great interest due to many real and potential applications. In these applications, titanium dioxide is used as a component of various types of composites of some significance in production of pharmaceuticals, cosmetics or paints [1,2], drug delivery systems with controlled release [3-5], solar cell [6-9], chemical sensing [10-12], luminescent material, and photocatalyst for, e.g., water purification [13-16]. In the wide field of organic-inorganic composite materials, titanium dioxide is a popular filler of organic matrices. The combination of $\mathrm{TiO}_{2}$ with polymer results in new and often unique properties, unapproachable for the individual components.

Direct mixing is the simplest way to produce polymer$\mathrm{TiO}_{2}$ nanocomposites [17-22]. However, the achievement of uniform dispersion of the hydrophilic inorganic phase in a hydrophobic organic polymer causes a lot of problems. The host-guest interactions are in this case very weak and based only on hydrogen bonds and van der Waals forces. A high surface energy of inorganic particles is responsible for their tendency to aggregate. In most cases, surface modification of the inorganic phase is an important part of the procedure. A way to reach stronger chemical bonds and reduction of aggregation is the use of the sol-gel process [22-26]. This process is based mainly on titanium alkoxide which, after hydrolysis and condensation, produces the desired crystal structure of $\mathrm{TiO}_{2}$.

The dispersed phase morphology can be controlled by modification of the hydrolysis/polycondensation parameters, titanium dioxide precursor type and host-guest interaction nature. A frequent polymer- $\mathrm{TiO}_{2}$ synthesis route is in situ emulsion polymerization, which leads to a good dispersion of the inorganic phase [27-29]. Titanium dioxide encapsulation in polymer, often results in a core-shell morphology [30]. On the other hand, polymers may be used as a specific reactor for preparation of $\mathrm{TiO}_{2}$ particles of 
dimensions mostly useful for specific applications [e.g., 31-33]. The performance of $\mathrm{TiO}_{2}$ microparticles in applications requires modeling of their morphology and porosity by controlling the parameters that influence the growth of oxide particles.

Recently, we applied preformed polymer particles as a support for synthesis of $\mathrm{SiO}_{2}$ mesoporous particles [34-36]. Silica particles were obtained by calcination and removal of polymer template from the polymer-silica nanocomposite being the product of swelling of pure polymer in silica precursor. In the present paper, a similar approach is applied for preparation of $\mathrm{Ti}^{4+} /$ polymer and $\mathrm{TiO}_{2}$ materials.

\section{Experimental}

\section{$\mathrm{TiO}_{2}$ preparation}

The composite samples were prepared by swelling of the commercial Amberlite XAD7HP (a nonionic aliphatic acrylic ester, Rohm and Haas, today DOW) beads (0.20.5 -mm fraction) in a solution of ethanol $(99.8 \% \mathrm{EtOH}$ solution supplied by Polish Chemical Reagents, POCH) with titanium (IV) ethoxide (Sigma-Aldrich, 98 wt.\%). A similar procedure was recently applied for preparation of polymer-silica composite using Amberlite XAD7HP or TRIM as a polymer and tetraethyl orthosilicate (TEOS) as a silica source [34-36]. Initially, the polymer beads were thoroughly washed with distilled water as the manufacturer suggests. Then the washed polymer XAD7HP was wetted with alcoholic solution of titanium (IV) ethoxide (70 \%). The amount of the titania precursor was adjusted so that the beads started to stick together, preserving a loosely packed structure. The resulting polymer/titanium (IV) ethoxide ratio was $0.5 \mathrm{w} / \mathrm{w}$. It can be assumed that part of the added titania precursor takes part in filling pores, and a part in the swelling process. Next, the Amberlite XAD7HP particles saturated with alcoholic solution of titanium (IV) ethoxide were transferred into aqueous ammonium hydroxide solution $\left(15 \mathrm{~cm}^{3}\right.$ of $25 \% \mathrm{NH}_{4} \mathrm{OH}$ solution supplied by Polish Chemical Reagents, $\mathrm{POCH}$ per $15 \mathrm{~g}$ of sample) and kept at room temperature for $24 \mathrm{~h}$ for gelation and ageing. The solid product in the form of spherically shaped particles was filtered, washed with deionized water, and dried at $110{ }^{\circ} \mathrm{C}$ under vacuum. No aggregation of these particles was observed. The drying procedure was performed for $12 \mathrm{~h}$. The dry composite sample obtained in the aforementioned manner was denoted as XADTi-B. In order to prepare pure $\mathrm{TiO}_{2}$, being the inorganic component of the composite, part of the base sample XADTi-B was calcined in air at $600^{\circ} \mathrm{C}$ for $12 \mathrm{~h}$. The remaining incombustible residue was denoted as Ti-B.

A similar procedure was applied to prepare the composite samples by hydrolysis and condensation of the titania precursor in distilled water $\left(15 \mathrm{~cm}^{3}\right.$ of distilled water per $15 \mathrm{~g}$ of sample). The dry water set was denoted as XADTi-N and its remaining incombustible part, after calcination in air at $600{ }^{\circ} \mathrm{C}$ was denoted as Ti-N.

Samples characterization

\section{Thermal analysis}

The mass loss TGA curves were measured using the Derivatograph C (MOM, Hungary) instrument. The samples were heated at the rate of $10 \mathrm{~K} \mathrm{~min}^{-1}$ from room temperature to $1,273 \mathrm{~K}$ in air flow.

\section{Scanning electron microscopy}

SEM studies were conducted on a Quanta ${ }^{\text {TM }}$ 3D FEG operating at a voltage of $30.0 \mathrm{kV}$.

\section{$\mathrm{N}_{2}$ adsorption}

Textural characterization of the samples was carried out by the low-temperature nitrogen adsorption-desorption method. Nitrogen adsorption-desorption measurements were made at $77 \mathrm{~K}$ using a volumetric adsorption analyzer ASAP 2405 (Micromeritics, Norcross, GA, USA). The specific surface areas, $S_{\mathrm{BET}}$, of the investigated samples were evaluated using the standard Brunauer-Emmett-Teller (BET) method for the nitrogen adsorption data in the range of a relative pressure $p / p_{o} 0.05$ to 0.25 . The total pore volumes were estimated from a single point adsorption at a relative pressure of 0.985 . The pore size distributions were obtained from the desorption branch of the isotherm using the Barrett-Joyner-Halenda (BJH) procedure [37].

\section{PALS experiment}

Positron annihilation lifetime spectroscopy (PALS) measurements were performed using fast-slow delayed coincidence spectrometer. The scintillator for detection of gamma quanta accompanying positron formation was $\varnothing 38 \times 51 \mathrm{~mm}$ $\mathrm{BaF}_{2}$, while annihilation radiation was detected by $\varnothing 38 \times$ $38 \mathrm{~mm} \mathrm{BaF}{ }_{2}$ crystal. As a positron source, $0.3 \mathrm{MBq}^{22} \mathrm{Na}$ enclosed in $8 \mu \mathrm{m}$ Kapton foil was used. Background to signal ratio was about 6-7\%. Positron fraction annihilating in the foil with lifetime 374 ps was found [38] to be approximately $12 \%$. Wide energy windows, set in order to maximize $3 \gamma$ annihilation radiation registration efficiency, allowed collecting $1.3 \times 10^{6}$ counts per hour. On the other hand, the energy window setup resulted in a complicated time resolution function, which had to be approximated by three Gaussians with FWHM 0.28, 0.35, and $0.75 \mathrm{ns,} \mathrm{and}$ intensity of $69 \%, 18 \%$, and $13 \%$, respectively. The spectra 
collected during the $23 \mathrm{~h}$ (about $3 \times 10^{7}$ counts) were analyzed using MELT routine $[39,40]$. Positron lifetime distributions were transformed to pore size distributions (PSDs) using the method described in $[35,41]$. All measurements were performed in vacuum about $10^{-3} \mathrm{~Pa}$.

\section{$X R D$}

$\mathrm{X}$-ray powder diffraction (XRD) patterns were measured on Dyfractometer HZG 4AZ (Germany) using monochromatic $\mathrm{CuK} \alpha$ radiation. The $\mathrm{X}$-ray patterns were scanned in $2 \Theta$ range of $10^{\circ}$ to $80^{\circ}$ with a step of $0.05^{\circ}$

\section{Results and discussion}

On the basis of the previous studies, it is known that porous polymers including the commercial Amberlite XAD7HP easily absorb the silica precursor TEOS. The molecular structure of the composite samples, porosity and their physical appearance are affected by the synthesis conditions [36]. The Amberlite XAD7HP polymer wetted with titanium (IV) ethoxide swells also spontaneously. Wetting of swollen $\mathrm{Ti}^{4+}$ / polymer particles in water of adjusted $\mathrm{pH}$ causes hydrolysis of titania precursor followed by condensation and finally, similarly as in the case of silica, $\mathrm{Ti}^{4+} /$ polymer composite formation. The pure $\mathrm{TiO}_{2}$ was obtained after composites calcination at $600{ }^{\circ} \mathrm{C}$. The TGA thermograms (Fig. 1) for composite XADTi-N and pure $\mathrm{TiO}_{2}(\mathrm{Ti}-\mathrm{N})$ clearly indicate that the polymer component after the thermal treatment at $600{ }^{\circ} \mathrm{C}$ for $12 \mathrm{~h}$ is completely removed. The microscopic SEM pictures of the composites (Fig. 2a) and calcined samples (Fig. 2b, c) indicate that the investigated particles preserve the spherical shape of the initial polymer. Moreover, the images illustrate that the hydrolysis and condensation conditions (basic and inert) influence the visual appearance of $\mathrm{Ti}^{4+} /$ polymer composites and pure $\mathrm{TiO}_{2}$ only slightly. The presence of cracks on the outer surface of particles is typical for samples after thermal treatment: Ti$\mathrm{N}$, Ti-B. Although the investigated samples preserve the

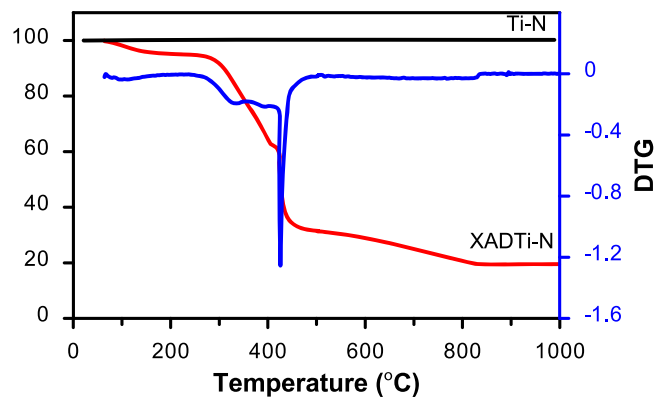

Fig. 1 TGA thermograms of composite XADTi-N and pure titanium dioxide Ti-N spherical shape of the initial polymer, the pure $\mathrm{TiO}_{2}$ particles have a more complex structure. The crushed titanium dioxide particle micrograph of Ti-B (Fig. 2c, d) demonstrates the core/shell structure.

Presumably, the core/shell structure of the $\mathrm{TiO}_{2}$ particles is a result of the specific titanium (IV) ethoxide hydrolysis and condensation in the presence of a polymer template. When swollen, Amberlite XAD7HP particles are transferred into water solution of desired $\mathrm{pH}$; the titania precursor present in the particle interior is partially excluded from these particles due to their shrinkage and condensation on the outer surface of the initial composite particle. Thus, it can be assumed that $\mathrm{Ti}^{4+} /$ polymer composite particles consist of two phases: $\mathrm{Ti}^{4+} /$ polymer, core and mesoporous pure $\mathrm{Ti}(\mathrm{OH})_{4}$, shell. Further condensation of titania species takes place during calcination at $600{ }^{\circ} \mathrm{C}$ accompanied by thermal decomposition of the polymer template. In line with this deduction, the observed characteristic cracks on the outer shell and inner core are the result of the heat treatment and shrinkage of the whole particles. However, the interior of the Ti-N (Fig. 2e) and Ti-B (not shown) beads is rather smooth and consists of tightly packed spherical particles of $\mathrm{TiO}_{2}$ sized from 11 to $20 \mathrm{~nm}$. The shell is composed of significantly larger spherical $\mathrm{TiO}_{2}$ particles (Fig. 2f). This clearly indicated that the sizes of the confined spaces in the polymer template have a great influence on the hydrolysis process and consequently on the size of the resulting $\mathrm{TiO}_{2}$ particles.

The XRD experiment results for the pure polymer matrix XAD7HP, composites, and pure $\mathrm{TiO}_{2}$ samples are shown in Fig. 3. No crystal peak was found prior to the calcination of the neutral and water set $\mathrm{Ti}^{4+} /$ polymer composite. Comparing these diffractograms, one can conclude that the introduction of a titanium precursor into polymer beads influences the arrangement of the hydrocarbon chains and reduces some regularity of the polymer matrix, what is visible as disappearance of broad peak at $2 \Theta=10-20^{\circ}$. The XRD patterns are practically identical for both calcined materials. The anatase structure is characteristic for Ti-N powder, while under the basic conditions, besides the anatase phase, a small amount of the rutile structure was found.

To determine the structure of nanocomposites as well as the final $\mathrm{TiO}_{2}$ particles, low temperature adsorption studies of nitrogen were carried out. Figure 4 shows the relevant nitrogen adsorption and desorption isotherms for original Amberlite XAD7HP support, $\mathrm{Ti}^{4+} /$ polymer composites (XADTi-N, XADTi-B) and pure titania oxide samples after calcination and total removal of polymer matrix (Ti-N, TiB). As regards the composite samples, it is easy to observe that the shape of their nitrogen isotherms differs only slightly. A steep rise in the initial part of these isotherms, for $p / p_{0}<0.02$, suggests the presence of micropores with dimensions smaller than $2 \mathrm{~nm}$. However, a wide hysteresis loop 
Fig. 2 SEM images of sample: XADTi-N (a), Ti-N (b), and TiB (c). Crushed Ti-B of core/ shell structure after thermal treatment at $600{ }^{\circ} \mathrm{C}(\mathbf{d})$, Ti-N sample inner beads part (e), and spherical particles on the outer surface (f)
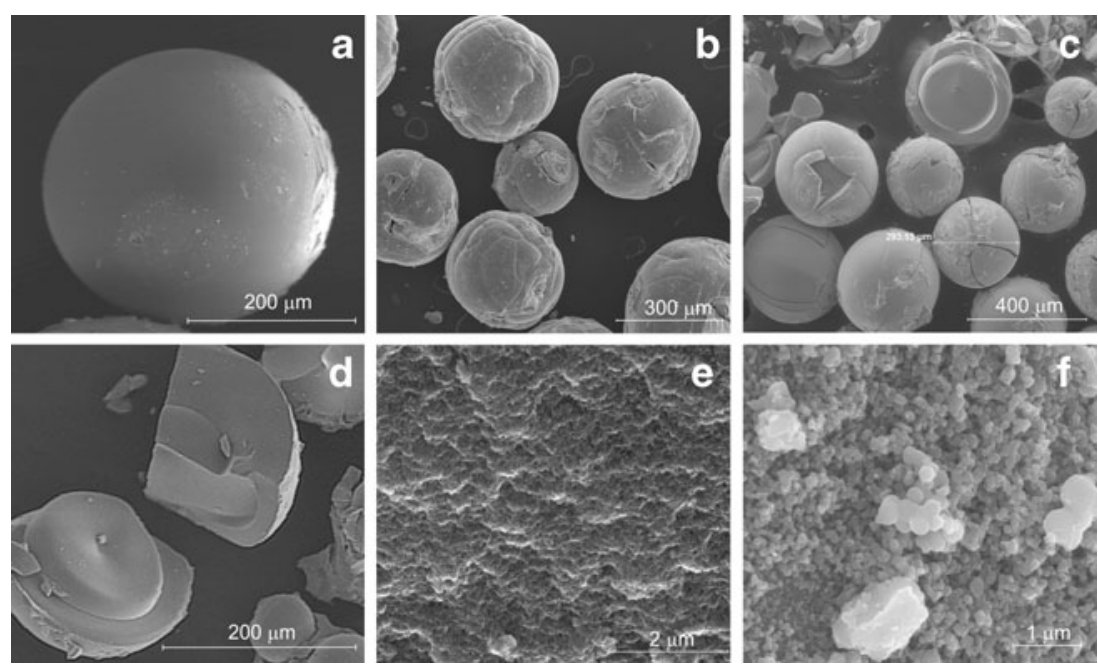

extending along the $p / p_{0}$ axis suggests a complex pore structure of these materials and the presence of mesopores of different dimensions. The different nitrogen adsorption of the composites and original Amberlite XAD7HP suggests that the titania precursor penetrated considerably the polymer pore network. In fact, the numerical parameters derived from the adsorption data presented in Table 1 show a substantial decrease of the total mesopore volume $\left(V_{\mathrm{p}}\right)$, average pore diameter $\left(D_{\mathrm{p}}\right)$ and BET surface area of the Amberlite after depositing the titania onto it under either basic (Fig. 4b) or neutral conditions (Fig. 4d). The decrease of these parameters suggests that $\mathrm{TiO}_{2}$ phase is entrapped mainly in mesopores of the initial polymer.

For calcined samples, after the Amberlite support removal at $600{ }^{\circ} \mathrm{C}$, the BET surface area $\left(S_{\mathrm{BET}}\right)$ substantially

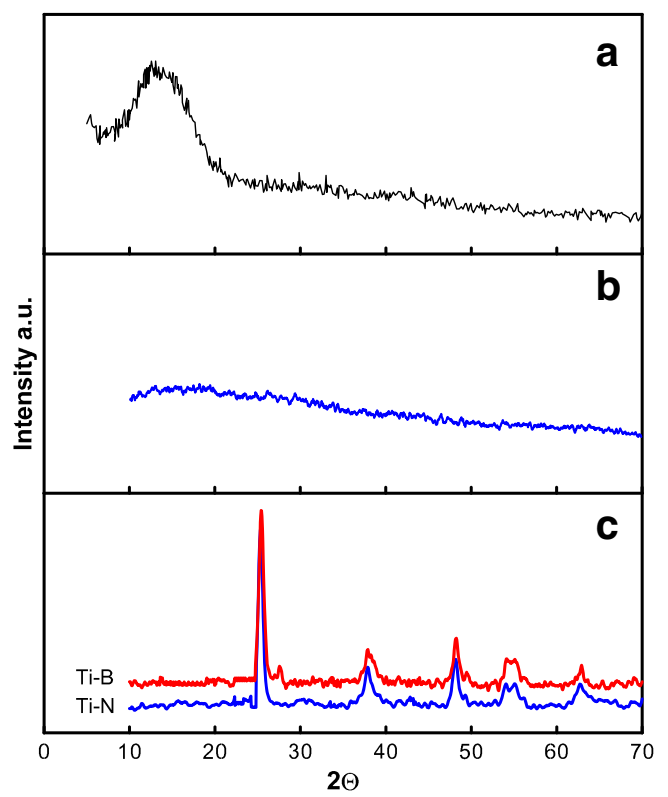

Fig. 3 XRD patterns of pure polymer Amberlite XAD7HP (a), composite $\mathrm{Ti}^{4+} /$ polymer XADTi-N (b), and pure titanium oxide Ti-N and Ti-B (c) decreased, while the average pore diameter $\left(D_{\mathrm{p}}=4 V_{\mathrm{p}} / S_{\mathrm{BET}}\right)$ and total pore volume $\left(V_{\mathrm{p}}\right)$ significantly increased as demonstrated by the data for Ti-B and Ti-N in Table 1. This may be caused by dissolution of smaller pore walls that leads to creation of bigger pores, which in fact represent free volumes occupied by the polymer before calcination.

The shape of isotherms for pure $\mathrm{TiO}_{2}$ samples obtained by calcination of composites is quite different from those for the composites, and they are of type 4 according to the IUPAC nomenclature [42]. The initial micropore adsorption at $p / p_{0}<0.01$ became substantially lower for the calcined samples as it was for composites XADTi-B and XADTi-N. Moreover, the observed hysteresis loop with approximately parallel adsorption and desorption branches (Fig. 4c, e), is characteristic for porous solids composed of spherical nanoparticles. One can therefore assume that nitrogen adsorption isotherms primarily relate to the pore structure of the outer layer of $\mathrm{TiO}_{2}$ particles.

Figure 4 also illustrates for all investigated samples the mesopore size distribution (PSD) derived from the $\mathrm{N}_{2}$ desorption data using the $\mathrm{BJH}$ method. As it can be seen, the PSD for pure polymer XAD7HP is of bimodal character, whereas the broad PSD of the base XADTi-B and neutral set XADTi-N nanocomposites is of a very heterogeneous porosity character. The observed shape of PSD curves for composites is related to the process of the titanium source hydrolysis in the confined spaces of the polymer template. The created particles of $\mathrm{TiO}_{2}$ in the polymer matrix are randomly packed causing the broad pore size distribution. However, for pure $\mathrm{TiO}_{2}$ samples, both PSDs show practically one well-defined peak, which suggests a high uniformity of the mesopore size.

In order to get more precise information about the pore structure, the discussed samples were investigated by means of PALS. Positronium annihilation lifetime spectroscopy is a technique which allows investigation of any free volumes in the range of diameters from angstroms to tens of nanometers. This method allows for determination of pore size in solids, 
Fig. 4 Low-temperature nitrogen adsorption (solid symbols) and desorption (open symbols) isotherms (left side) and pore size distributions derived from BJH procedure (right side) of investigated samples XAD7HP (a), XADTiB (b), Ti-B (c), XADTi-N (d), Ti-N (e)

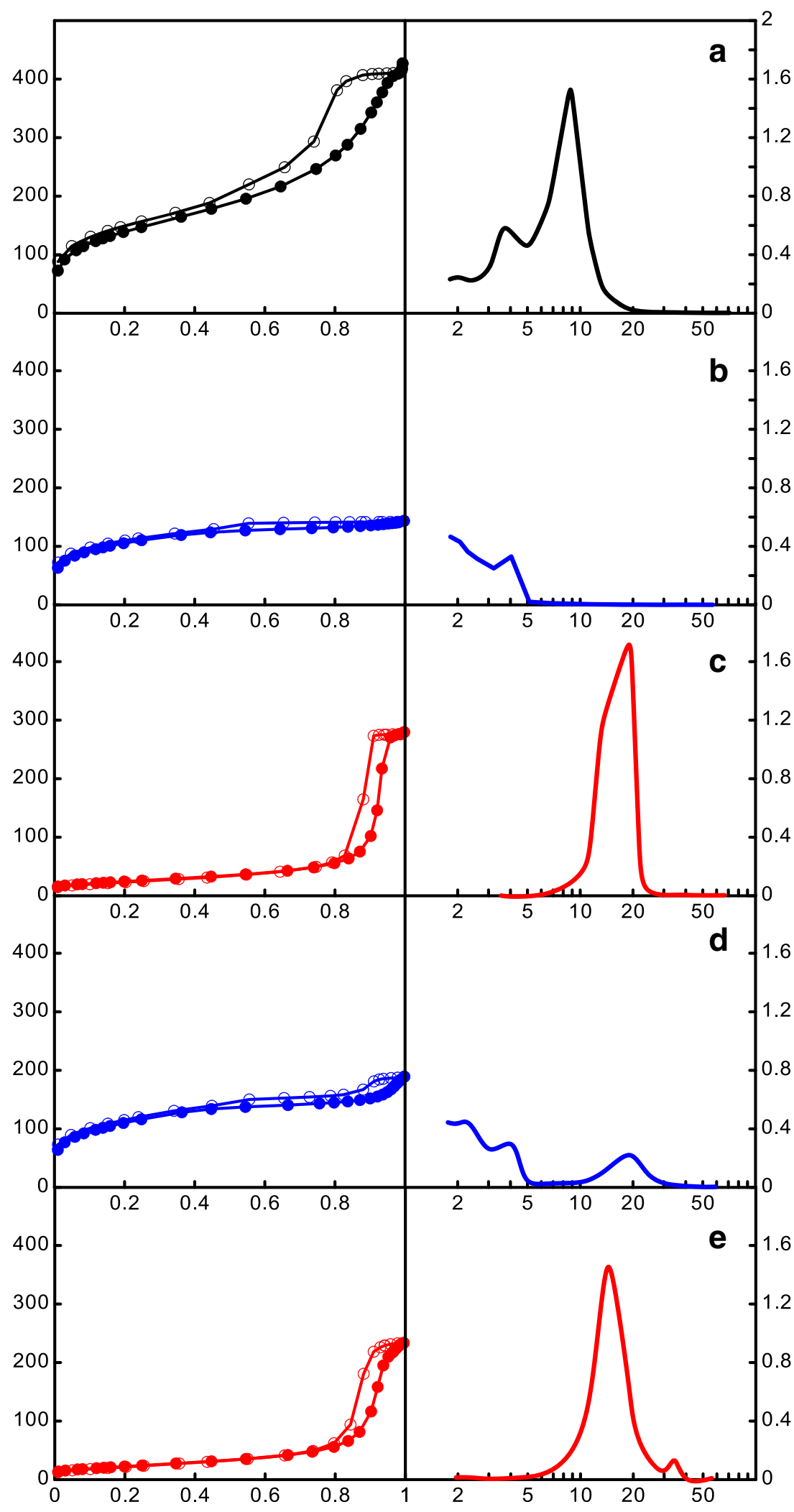

including closed pores and the space between fine particles or molecules. Determination of pore size on the basis of o-Ps lifetime for radii larger than $1 \mathrm{~nm}$ is possible due to the Extended Tao-Eldrup (ETE) model [43]. The ETE model was successfully applied for characterization of several model silicas or glasses of controlled porosity [44-48]. Moreover, the PALS technique can be used in a wide temperature range. The use of any adsorbate molecules and cooling the solid to a 
Table 1 Parameters characterizing the porosity of samples obtained from nitrogen adsorption/desorption measurements at $-195{ }^{\circ} \mathrm{C}$

\begin{tabular}{llcr}
\hline Sample name & $S_{\text {BET }}\left(\mathrm{m}^{2} / \mathrm{g}\right)$ & $V_{\mathrm{p}}\left(\mathrm{cm}^{3} / \mathrm{g}\right)$ & $D_{\mathrm{p}}(\mathrm{nm})$ \\
\hline AmberliteXAD7HP & 500 & 0.64 & 5.12 \\
XADTi-B & 376 & 0.22 & 2.34 \\
Ti-B & 86 & 0.43 & 20.00 \\
XADTi-N & 394 & 0.28 & 2.84 \\
Ti-N & 79 & 0.36 & 18.23 \\
\hline
\end{tabular}

low temperature, as is practiced by the conventional nitrogen adsorption method, are not required. This allows avoiding shrinkage of the solid pore network at a low temperature. This effect can be especially important for porous polymers and composites.

Figure 5 presents the pore size distribution of pure polymer, composite XADTi-N, and pure $\mathrm{TiO}_{2}$ calculated on the basis of PALS measurements. The PSDs of XADTi-B composite and Ti-B are not shown for clarity but are almost identical with those presented in Fig. 5 for samples synthesized in neutral conditions. As can be seen in Fig. 5b, the introduction of titanium precursor into the polymer beads causes the disappearance of mesopores of diameter above $3 \mathrm{~nm}$. The PSD for the composite sample XADTi-N exhibits the presence of at least four groups of pores within a wide dimension range of $0.3-2.5 \mathrm{~nm}$. After calcination and total burning of the polymer matrix (Fig. 5c), these small pores disappear and one can observe the appearance of a new group of pores of PSD centered at $10 \mathrm{~nm}$. The disappearance of the smallest pores group clearly indicates that they originate from the polymer constituent. The mesopores remaining in pure $\mathrm{TiO}_{2}$ sample

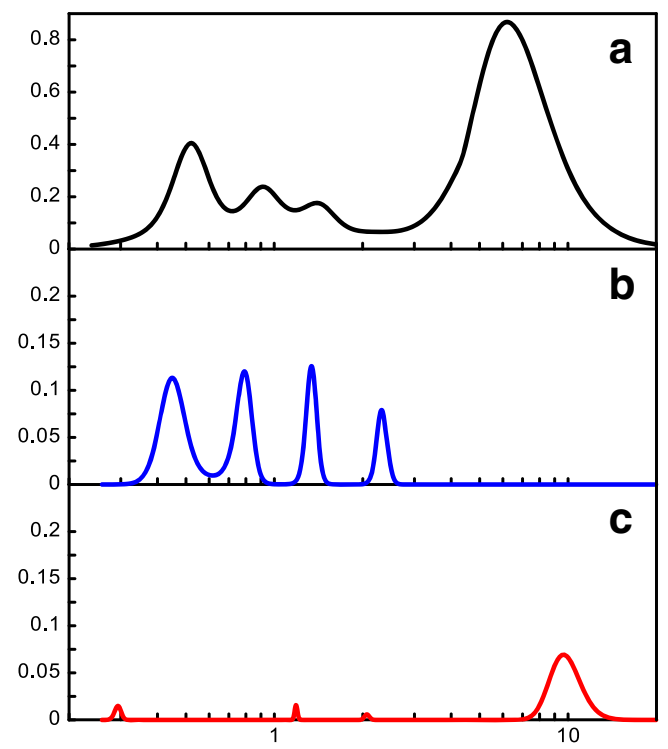

Fig. 5 Pore size distribution calculated from positron annihilation lifetime spectra for the XAD7HP (a), composite XADTi-N (b), and pure titanium oxide Ti-N (c)

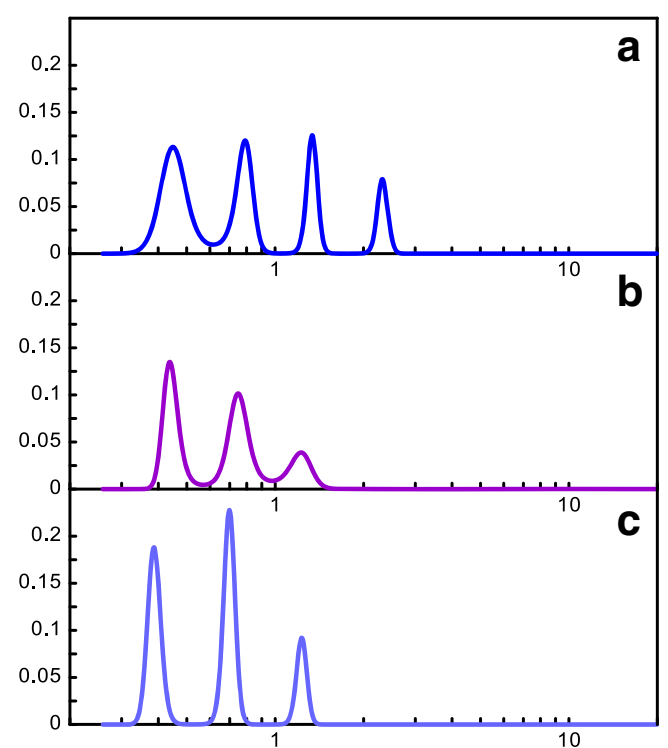

Fig. 6 Dependence of the free volume dimensions versus temperature of XADTi-N (a), XADTi-N at $200{ }^{\circ} \mathrm{C}(\mathbf{b})$ and XADTi-N after cooling to RT (c)

after calcination at $600{ }^{\circ} \mathrm{C}$ correspond probably to the free volumes between $\mathrm{TiO}_{2}$ submicroparticles formed during condensation of $\mathrm{Ti}(\mathrm{OH})_{4}$.

The interesting dependence of the free volume dimensions at different temperatures observed in composite samples is worth mentioning. Figure 6 presents pore volume distributions measured in vacuum for the composite obtained under neutral conditions at room temperature (Fig. 6a), at $200{ }^{\circ} \mathrm{C}$ (Fig. 6b) and after cooling again to room temperature (Fig. $6 \mathrm{c}$ ). One can easily observe that the peak at $D=2.5 \mathrm{~nm}$ disappears during heating of the composite up to $200{ }^{\circ} \mathrm{C}$. The disappearance of the peak observed for the nanocomposite at room temperature testifies that simultaneously two processes take place during heating. Firstly, at about $200{ }^{\circ} \mathrm{C}$, the $\mathrm{Ti}(\mathrm{OH})_{4}$ condenses and amorphous $\mathrm{TiO}_{2}$ starts to form. Additionally, at this temperature, the polymer matrix is more flexible and starts to stick more tightly to the incipient $\mathrm{TiO}_{2}$ phase. This structure modification is preserved after cooling the sample down to room temperature. On the other hand, the high temperature does not influence substantially the pores of smaller size $D<$ $2 \mathrm{~nm}$, which corresponds to the free volumes within the polymer matrix, indicating that the internal structure of the polymer remains almost intact at $200^{\circ} \mathrm{C}$.

\section{Conclusions}

The porous polymer $/ \mathrm{Ti}^{4+}$ microspheres were prepared by polymer particle saturation with titanium (IV) ethoxide followed by its condensation. The obtained composites exhibit a relatively high porosity and preserved the spherical shape of the initial 
polymer particles. Encapsulation of inorganic particles is a result of pore filling with tetraethoxy titania precursor and entrapping of the precursor molecules in the polymer matrix. Both specific surface areas and the total pore volume of the composite materials are slightly reduced as compared to pure polymer. Thus, polymer swelling in titania precursor allows us to control the particle dimensions of the composite and pure $\mathrm{TiO}_{2}$ by using preformed polymer particles of tailored porosity. Thermal treatment of composites at $200{ }^{\circ} \mathrm{C}$ causes their structural reorganization and a tight packing of the polymer and titania component. After heat treatment at $600{ }^{\circ} \mathrm{C}$ and elimination of the organic component from $\mathrm{Ti}^{4+} /$ polymer composite, a stable structure of $\mathrm{TiO}_{2}$ particles was achieved. $\mathrm{TiO}_{2}$ particles were composed mainly of anatase nanocrystals sized between 20 and $40 \mathrm{~nm}$. Structural analysis of $\mathrm{TiO}_{2}$ indicates a good dispersion of $\mathrm{TiO}_{2}$ precursor within preformed polymer beads and well-developed mesoporosity of pure $\mathrm{TiO}_{2}$ particles.

Acknowledgments The research was carried out with the equipment purchased thanks to the financial support of the European Regional Development Fund in the framework of the Polish Innovation Economy Operational Program (contract no. POIG.02.01.00-06-024/09 Center of Functional Nanomaterials).

Open Access This article is distributed under the terms of the Creative Commons Attribution License which permits any use, distribution, and reproduction in any medium, provided the original author(s) and the source are credited.

\section{References}

1. Balfour JG (1994) Technological applications of dispersions. Marcel Dekker, New York

2. Nasu A, Otsubo Y (2007) Rheology and UV-protecting properties of complex suspensions of titanium dioxides and zinc oxides. J Colloid Interface Sci 310:617-623

3. Peterson A, López T, Islas EO, Gonzalez RD (2007) Pore structures in an implantable sol-gel titania ceramic device used in controlled drug release applications: a modeling study. Appl Surf Sci 253:5767-5771

4. Uddin MJ, Mondal D, Morris CA, Lopez T, Diebold U, Gonzalez RD (2011) An in vitro controlled release study of valproic acid encapsulated in a titania ceramic matrix. Appl Surf Sci 257:79207927

5. López T, Ortiz E, Meza D, Basaldell E, Bokhimi X, Magana C, Sepulveda A, Rodriguez F, Ruiz J (2011) Controlled release of phenytoin for epilepsy treatment from titania and silica based materials. Mater Chem Phys 126:922-929

6. Fujihara K, Kumar A, Jose R, Ramakrishna S, Uchida S (2007) Spray deposition of electrospun $\mathrm{TiO}_{2}$ nanorods for dye-sensitized solar cell. Nanotechnology 18:365709

7. Grätzel M (2009) Recent advances in sensitized mesoscopic solar cells. Chem Res 42:1788-1798

8. Melcarne G, De Marco L, Carlino E, Martina F, Manca M, Cingolani R, Gigli G, Ciccarella G (2010) Surfactant-free synthesis of pure anatase $\mathrm{TiO}_{2}$ nanorods suitable for dye-sensitized solar cells. J Mater Chem 20:7248-7254

9. Huang CH, Yang YT, Doong RA (2011) Microvave-assisted hydrothermal synthesis of mesoporous anatase $\mathrm{TiO}_{2}$ via sol-gel process for dye-sensitized solar cells. Microporous Mesoporous Mater 142:473-480

10. Paulose M, Varghese OK, Mor GK, Grimes CA, Ong KG (2006) Unprecedented ultra-high hydrogen gas sensitivity in undoped titania nanotubes. Nanotechnol 17:398-402

11. Wang G, Wang Q, Lu W, Li JH (2006) Photoelectrochemical study on charge transfer properties of $\mathrm{TiO}_{2}-\mathrm{B}$ nanowires with an application as humidity sensors. J Phys Chem B 110:2202922034

12. Yang G, Hu P, Cao Y, Yuan F, Xu R (2010) Fabrication of porous $\mathrm{TiO} 2$ hollow spheres and their application in gas sensing. Nanoscale Res Lett 5:1437-1441

13. Chang S, Doong R (2006) Characterization of Zr-doped $\mathrm{TiO} 2$ nanocrystals prepared by a nonhydrolytic, sol-gel method at high temperatures. J Phys Chem B 110:20808-20814

14. Iskandar F, Nandiyanto ABD, Yun KM, Hogan CJ, Okuyama K, Biswas P (2007) Enhanced photocatalytic performance of brookite $\mathrm{TiO}_{2}$ macroporous particles prepared by spray drying with colloidal templating. Adv Mater 19:1408-1412

15. Kao L, Hsu TC, Cheng K (2010) Novel synthesis of highsurface-area ordered mesoporous $\mathrm{TiO}_{2}$ with anatase framework for photocatalytic applications. J Colloid Interface Sci 341:359365

16. Yu J, Zhang J (2010) A simple template-free approach to $\mathrm{TiO}_{2}$ hollow spheres with enhanced photocatalytic activity. Dalton Trans 39:5860-5867

17. Ma D, Akpalu YA, Li Y, Siegel RW, Schadler LS (2005) Effect of titania nanoparticles on the morphology of low density polyethylene. J Polym Sci B 43:488-497

18. Nussbaumer RJ, Caseri WR, Smith P, Tervoort T (2003) Polymer$\mathrm{TiO} 2$ nanocomposites: a route towards visually transparent broadband UV filters and high refractive index materials. Macromol Mater Eng 288:44-49

19. Boccaccini AR, Gerhardt L-C, Rebeling S, Blaker JJ (2005) Fabrication, characterisation and assessment of bioactivity of poly(d, 1 lactid acid) (PDLLA)/TiO2 nanocomposite films. Compos A: Appl Sci Manuf 36:721-727

20. Huang KS, Nien YH, Chen JS, Shieh TR, Chen JW (2006) Synthesis and properties of epoxy/TiO2 composite materials polym. Compos 27:195-200

21. Wang Z, Li G, Peng H, Zhang Z (2005) Study on novel antibacterial high-impact polystyrene/TiO2 nanocomposites. J Mater Sci 40:6433-6438

22. Yu LY, Shen HM, Xu ZL (2009) PVDF-TiO2 composite hollow fiber ultrafiltration membranes prepared by sol-gel method and blending method. J Appl Polym Sci 113:1763-1772

23. Zheng MP, JinYP JGL, Gu MY (2000) Characterization of TiO2PVP nanocomposites prepared by the sol-gel method. J Mater Sci Letters 19:433-436

24. Chen WC, Lee LH, Chen BF, Yen CT (2002) Synthesis and characterization of poly(methyl silsesquioxane)-titania optical thin films. J Mater Chem 12:3644-3648

25. Sarwar MI, Zulfiqar S, Ahmad Z (2007) Preparation and properties of polyamide-titania nanocomposites. J Sol-gel. Part Sci Technol 44:41-46

26. Bahloul W, Bounor-Legaré V, David L, Cassagnau P (2010) Morphology and viscoelasticity of $\mathrm{PP} / \mathrm{TiO} 2$ nanocompsites prepared by in situ sol-gel method. J Polym Sci Part B 48:12131222

27. Džunuzowić E, Marinović-Cincović M, Vuković J, Jeramić K, Nedeljković JM (2009) Thermal properties of PMMA/TiO2 nanocomposites prepared by in-situ bulk polymerization. Polym Comp 30:737-742

28. Zhuang W, Liu J, Zhang JH, Hu BX, Shen J (2009) Preparation, characterization, and properties of TiO2/PLA nanocomposites by in situ polymerization. Polym Comp 30:1074-1080 
29. Messina PV, Verdinelli V, Pieroni O, Ruso JM (2012) Role of interfacial elasticity of microemulsions on the morphology of $\mathrm{TiO}_{2}$ nanostructures: stiff templates versus flexible templates. Colloid Polym Sci. doi:10.1007/s00396-012-2798-4

30. Li L, Qin D, Yang X, Liu G (2011) Synthesis of titania/polymer core-shell hybrid microspheres. Colloid Polym Sci 288:199-206

31. Balaji T, Matsunaga H (2002) Adsorption characteristics of As(III) and $\mathrm{As}(\mathrm{V})$ with titanium dioxide loaded Amberlite XAD-7 resin. Analyt Sci 18:1345-1348

32. Dai R, Wu G, Chen H (2011) Stable titanium dioxide grafted with poly [N-(p-vinyl benzyl) phthalimide] composite particles in suspension for electrophoretic displays. Colloid Polym Sci 289:401-407

33. Szymanski L, Surolia P, Byrne O, Thampi KR, Stubenrauch $\mathrm{C}$ (2012) Porous "sponge-like" anatase $\mathrm{TiO}_{2}$ via polymer templates: synthesis, characterization, and performance as a light-scattering material. Colloid Polym Sci. doi:10.1007/s00396-012-2792-x

34. Kierys A, Dziadosz M, Goworek J (2010) Polymer/silica composite of core-shell type by polymer swelling in TEOS. J Colloid Interface Sci 349:361-365

35. Zaleski R, Kierys A, Grochowicz M, Dziadosz M, Goworek J (2011) Synthesis and characterization of nanostructural polymersilica composite: positron annihilation lifetime spectroscopy study. J Colloid Interf Sci 358:268-276

36. Halasz I, Kierys A, Goworek J, Liu H, Patterson RE (2011) 29Si NMR and Raman glimpses into the molecular structures of acid and base set silica gels obtained from TEOS and Na-silicate. J Phys Chem C 115:24788-24799

37. Barrett EP, Joyner LG, Halenda PP (1951) The determination of pore volume and area distributions in porous substances. I. Computations from nitrogen isotherms. J Am Chem Soc 73 (1):373-380

38. Djourelov N, Misheva M (1996) Source correction in positron annihilation lifetime spectroscopy. J Phys Condens Matter 8:2081-2087
39. Shukla A, Peter M, Hoffmann L (1993) Analysis of positron lifetime spectra using quantified maximum entropy and a general linear filter. Nucl Inst Methods Phys Res A 335:310-317

40. Zaleski R (2006) Measurement and analysis of the positron annihilation lifetime spectra for mesoporous silica. Acta Phys Polon A 110:729-738

41. Zaleski R, Stefaniak W, Maciejewska M, Goworek J (2010) Porosity evolution of VP-DVB/MCM-41 nanocomposite. J Coll Interf Sci 343(1):134-140

42. Sing KSW, Everett DH, Mouscou RAWL, Pierotti RA, Rouquerol J, Siemieniewska J (1985) Reporting physisorption data for gas/ solid systems with special reference to the determination of surface area and porosity. Pure Appl Chem 57:603-619

43. Goworek T, Ciesielski K, Jasińska B, Wawryszczuk J (1998) Positronium states in the pores of silica gel. Chem Phys 230:305-315

44. Kullmann J, Enke D, Thraenert S, Krause-Rehberg R, Inayat A (2010) Characterization of nanoporous monoliths using nitrogen adsorption and positronium annihilation lifetime spectroscopy. Colloids Surf, A Physicochem Eng Asp 357(1-3):17-20

45. Thraenert S, Hassan EM, Enke D, Fuerst D, Krause-Rehberg R (2007) Verifying the RTE model: ortho-positronium lifetime measurement on controlled pore glasses. Phys Stat Solidi C 4 (10):3819-3822

46. Koshimizu M, Shimokita K, Zhou HS, Honma I, Asai K (2008) Positron annihilation lifetime in ordered porous silica SBA-3. J Phys Chem C 112(24):8779-8783

47. Kunishige S, Koshimizu M, Asai K (2009) Temperature dependence of positron lifetime in ordered porous silica (SBA-3). Radiat Phys Chem 78(12):1088-1091

48. Hill MR, Pas SJ, Mudie ST, Kennedy DF, Hill AJ (2009) Internal and external surface characterisation of templating processes for ordered mesoporous silicas and carbons. J Mater Chem 19:22152225 